\title{
A STUDY OF USEFULNESS OF PSYCHOMETRIC TESTS IN DIAGNOSIS OF MINIMAL HEPATIC ENCEPHALOPATHY IN PATIENTS WITH CIRRHOSIS OF LIVER
}

\author{
1 Professor, Department of Medicine, Government Stanley Medical College. \\ ${ }^{2}$ Associate Professor, Department of Medicine, Government Stanley Medical College. \\ ${ }^{3}$ Associate Professor, Department of Medicine, Government Stanley Medical College. \\ ${ }^{4}$ Assistant Professor, Department of Medicine, Government Stanley Medical College.
}

Sundaramurthy Ganesan"1, Ashok Kumar Subramaniam², Natarajan Kandasamy33, Vijayanand Radhakrishnan ${ }^{4}$

\section{ABSTRACT}

\section{BACKGROUND}

Hepatic encephalopathy (HE) is a potentially reversible, metabolically caused disturbance of central nervous system function that occurs in patients with acute or chronic liver disease. It encompasses a board spectrum of neurological symptoms of varying severity and is classified according to clinical symptoms. Minimal hepatic encephalopathy (MHE), previously known as subclinical or latent hepatic encephalopathy, is at the beginning of this spectrum. MHE has a high prevalence among patients with liver cirrhosis (22\% to $74 \%) .{ }^{1}$ It is defined as HE without symptoms on clinical/neurological examination, but with deficits in some cognitive areas that can only be measured by neuropsychometric testing and critical flicker frequency test. The areas with impairments are attention, visuospatial perception, speed of information processing, especially in the psychomotor area, fine motor skills, and short-term memory leading to impaired quality of life and ability to work associated with driving errors, accidents and further deterioration into overt encephalopathy and thereby with increased mortality. In our study, we study the effectiveness of Psychometric tests and Critical flicker frequency test in detecting minimal hepatic encephalopathy earlier in patients with cirrhosis. ${ }^{1}$

\section{MATERIALS AND METHODS}

This study has been carried out at the General Medicine OP and wards, Department of MGE OP and wards at Govt. Stanley Hospital, Chennai.

Study Period- Six months (From June 2013 to November 2013).

Study Design- This is a Prospective Observational Study.

\section{CONCLUSION}

Our study demonstrated the occurrence of Minimal Hepatic Encephalopathy (MHE) in patients with Cirrhosis irrespective of the aetiology even in the presence of stable clinical condition. Both Critical Flicker Frequency (CFF) and Psychometric tests have been found out to be effective in detecting MHE. Psychometric tests have subjective variations due to their age factor, differences in education while CFF Test has no such limitations and more of objective in nature not requiring any educational qualification for undergoing and interpretation of the light stimulus and is reproducible. The detection of MHE in more numbers in our study may be due to higher number of patients with higher classes of Child-Pugh classification. The presence of majority of the patients with Hepatitis B infection is due to our place of study being a tertiary care and a prestigious institute of Gastroenterology.

Hence, we would like to recommend the utilisation of Critical Flicker Frequency (CFF) Test as an Outpatient Department based screening procedure and also for the monitoring of patients with cirrhosis yet with a stable clinical condition so as to detect MHE earlier and promptly institute the therapy to avoid the complications.

\section{KEYWORDS}

Hepatic Encephalopathy, Cirrhosis, Psychometric Tests.

HOW TO CITE THIS ARTICLE: Ganesan S, Subramaniam A, Kandasamy N, et al. A study of usefulness of psychometric tests in diagnosis of minimal hepatic encephalopathy in patients with cirrhosis of liver. J. Evolution Med. Dent. Sci. 2016;5(79):5889-5893, DOI: $10.14260 /$ jemds/2016/1329

\section{INTRODUCTION}

Hepatic encephalopathy (HE) is a potentially reversible, metabolically caused disturbance of central nervous system function that occurs in patients with acute or chronic liver

Financial or Other, Competing Interest: None.

Submission 19-08-2016, Peer Review 20-09-2016,

Acceptance 26-09-2016, Published 01-10-2016.

Corresponding Author:

Dr. Ashok Kumar Subramaniam,

No.41, GST Road,

Meenambakkam,

Chennai-600027.

E-mail: drashokstanley2459@gmail.com

DOI: $10.14260 /$ jemds $/ 2016 / 1329$

\section{(c) $($ ) $९$}

disease. It encompasses a board spectrum of neurological symptoms of varying severity and is classified according to clinical symptoms. Minimal hepatic encephalopathy (MHE), previously known as subclinical or latent hepatic encephalopathy, is at the beginning of this spectrum. MHE has a high prevalence among patients with liver cirrhosis $(22 \%$ to $74 \%){ }^{1}$ It is defined as $\mathrm{HE}$ without symptoms on clinical/neurological examination, but with deficits in some cognitive areas that can only be measured by neuropsychometric testing and critical flicker frequency test.

The areas with impairments are attention, visuospatial perception, speed of information processing, especially in the psychomotor area, fine motor skills, and short-term memory leading to impaired quality of life and ability to work 
associated with driving errors, accidents and further deterioration into overt encephalopathy and thereby with increased mortality. In our study, we study the effectiveness of psychometric tests and critical flicker frequency test in detecting minimal hepatic encephalopathy earlier in patients with cirrhosis.

\section{MATERIALS AND METHODS}

\section{Place of Study}

This study has been carried out at the General Medicine OP and wards, Department of MGE OP and wards at Govt. Stanley Hospital, Chennai.

\section{Study Period}

Six months (From June 2013 to November 2013).

\section{Study Design}

This is a Prospective Observational Study.

\section{Ethical Committee Approval}

The ethical committee approval was obtained for this study.

\section{PATIENT SELECTION}

\section{Inclusion Criteria}

1. Age more than 18 years and below 70 years.

2. All patients who have been diagnosed as cirrhosis of the liver and detected by clinical, serological, biochemical, assessments and USG.

\section{Exclusion Criteria}

1. Patients aged below 18 years and above 70 years.

2. Patients with overt hepatic encephalopathy had variceal bleed within 6 weeks.

3. Patients diagnosed with Hepatocellular Carcinoma.

4. Patients who had undergone TIPS or shunt surgery.

5. Patients who had taken alcohol in last 6 weeks.

6. Known Patients with cognitive impairment disorders as Alzheimer's disease, Parkinsonism.

7. Patients who are already taking sedatives, antidepressants.

8. Patients with impairment of vision.

\section{METHODOLOGY}

100 patients who have been diagnosed with cirrhosis based on clinical, biochemical, serological and ultrasonogram visiting in Medicine OP, MGE OP and admitted in Medical wards and MGE wards and 50 normal people as control group from June 2013 to November 2013 are included in the study. Patients were subjected to symptom analysis, clinical examination, laboratory investigations, psychometric tests and critical flicker frequency test to establish the current degree of encephalopathy. The final analysis was made at the end of the study to achieve the aforementioned goal.

\section{DISCUSSION}

This study includes 150 patients with 100 people as proven cases of cirrhosis and 50 people as controls for the psychometric tests. All the patients under the study were found to have no neurological disorder or psychiatric illness.

\begin{tabular}{|c|c|c|c|c|}
\hline Sex & Cases & Percentage & Controls & Percentage \\
\hline Male & 76 & $76 \%$ & 32 & $64 \%$ \\
\hline Female & 24 & $24 \%$ & 18 & $36 \%$ \\
\hline Total & $\mathbf{1 0 0}$ & & $\mathbf{5 0}$ & \\
\hline
\end{tabular}

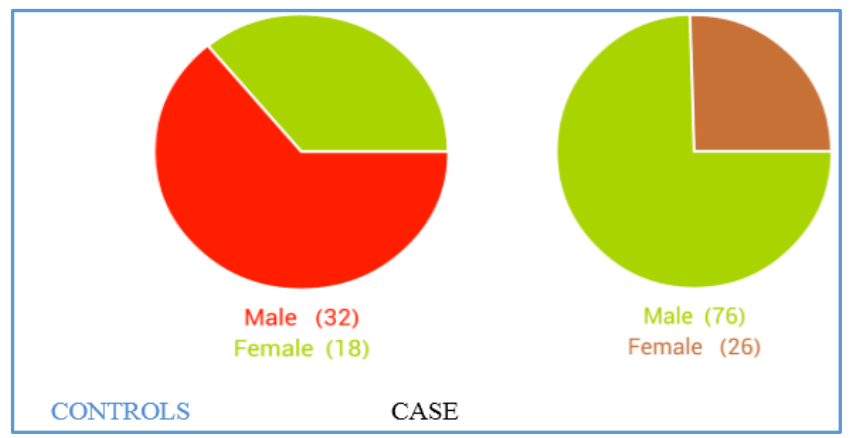

\begin{tabular}{|c|c|c|c|c|}
\hline & Group & N & Mean & Std. Deviation \\
\hline Age in years & Control & 50 & 40.38 & 11.820 \\
\hline & Study & 100 & 41.03 & 12.333 \\
\hline
\end{tabular}

There were 76 males and 24 females in the study group. There were 32 males and 18 females in the control group. In both the groups, the predominance of males is seen.

Mean age of presentation is 40 years with the youngest being 19 years and oldest 69 years. The mean age of study group is 41 years and of controls is 40 years.

\section{PSYCHOMETRIC TESTS}

\begin{tabular}{|c|c|c|c|c|}
\hline & Group & $\mathbf{N}$ & Mean & Std. Deviation \\
\hline NCT-A & Control & 50 & 57.38 & 9.243 \\
\hline & Study & 100 & 85.81 & 31.746 \\
\hline NCT-B & Control & 50 & 152.34 & 19.448 \\
\hline & Study & 100 & 224.07 & 55.332 \\
\hline DST & Control & 50 & 194.46 & 34.929 \\
\hline & Study & 100 & 270.38 & 49.218 \\
\hline LTT & Control & 50 & 575.60 & 38.255 \\
\hline & Study & 100 & 662.62 & 62.555 \\
\hline SDT & Control & 50 & 207.40 & 96.533 \\
\hline & Study & 100 & 271.28 & 76.997 \\
\hline CFF (Hz) & Control & 50 & 47.882 & 4.6541 \\
\hline & Study & 100 & 36.866 & 3.7761 \\
\hline CFF(SD) & Control & 50 & 1.5770 & .74642 \\
\hline & Study & 100 & 1.2390 & .70188 \\
\hline
\end{tabular}

There exists significant difference in the performance of all the Psychometric tests as indicated by the values of median and standard deviation when compared between the study and the control groups $(\mathrm{p}=0.000)$.

\section{NCT-A * Group}

\begin{tabular}{|c|c|c|c|c|c|}
\hline & & \multicolumn{2}{|c|}{ Group } & \multirow{2}{*}{ Total } \\
\hline & & & Control & Study & \\
\hline \multirow{5}{*}{ NCT-A } & \multirow{3}{*}{$+\mathrm{Ve}$} & Count & 0 & 17 & 17 \\
\hline & & $\begin{array}{c}\% \\
\text { within } \\
\text { NCT-A }\end{array}$ & $0 \%$ & $100.0 \%$ & $100.0 \%$ \\
\hline & & $\begin{array}{c}\quad \% \\
\text { within } \\
\text { Group }\end{array}$ & $0 \%$ & $17.0 \%$ & $11.3 \%$ \\
\hline & \multirow[b]{2}{*}{-Ve } & Count & 50 & 83 & 133 \\
\hline & & $\begin{array}{c}\quad \% \\
\text { within } \\
\text { NCT-A }\end{array}$ & $37.6 \%$ & $62.4 \%$ & $100.0 \%$ \\
\hline
\end{tabular}




\begin{tabular}{|c|c|c|c|c|c|}
\hline & $\begin{array}{c}\% \\
\text { within } \\
\text { Group }\end{array}$ & $100.0 \%$ & $83.0 \%$ & $88.7 \%$ \\
\hline \multirow{5}{*}{ Total } & Count & 50 & 100 & 150 \\
\cline { 2 - 5 } & $\begin{array}{c}\% \\
\text { within } \\
\text { NCT-A }\end{array}$ & $33.3 \%$ & $66.7 \%$ & $100.0 \%$ \\
\cline { 2 - 5 } & $\begin{array}{c}\% \\
\text { within } \\
\text { Group }\end{array}$ & $100.0 \%$ & $100.0 \%$ & $100.0 \%$ \\
\hline
\end{tabular}

Number Connection Test -A was positive in only study group with no positivity at all in the control group.

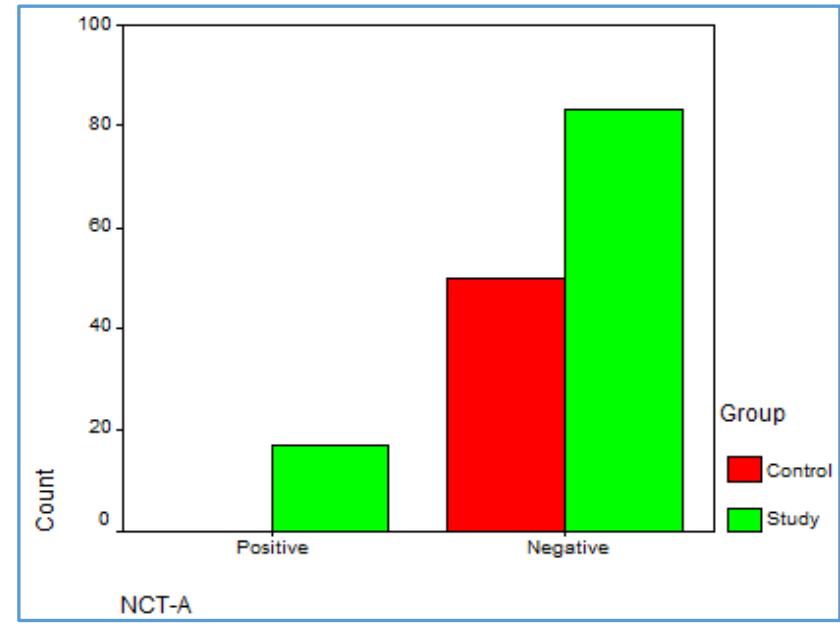

NCT-A Test turned out to be positive in only study group.

\begin{tabular}{|c|c|c|c|c|c|}
\hline & & \multicolumn{2}{|c|}{ Group } & \multirow{2}{*}{ Total } \\
\hline & & & Control & Study & \\
\hline \multirow{6}{*}{$\begin{array}{c}\text { NCT- } \\
\text { B }\end{array}$} & \multirow{3}{*}{$+\mathrm{Ve}$} & Count & 0 & 60 & 60 \\
\hline & & $\begin{array}{c}\text { \% within } \\
\text { NCT-B }\end{array}$ & $.0 \%$ & $100.0 \%$ & $100.0 \%$ \\
\hline & & $\begin{array}{l}\text { \% within } \\
\text { Group }\end{array}$ & $.0 \%$ & $60.0 \%$ & $40.0 \%$ \\
\hline & \multirow{3}{*}{-Ve } & Count & 50 & 40 & 90 \\
\hline & & $\begin{array}{c}\% \text { within } \\
\text { NCT-B }\end{array}$ & $55.6 \%$ & $44.4 \%$ & $100.0 \%$ \\
\hline & & $\begin{array}{c}\text { \% within } \\
\text { Group }\end{array}$ & $100.0 \%$ & $40.0 \%$ & $60.0 \%$ \\
\hline \multirow{3}{*}{\multicolumn{2}{|c|}{ Total }} & Count & 50 & 100 & 150 \\
\hline & & $\begin{array}{c}\% \text { within } \\
\text { NCT-B }\end{array}$ & $33.3 \%$ & $66.7 \%$ & $100.0 \%$ \\
\hline & & $\begin{array}{c}\text { \% within } \\
\text { Group }\end{array}$ & $100.0 \%$ & $100.0 \%$ & $100.0 \%$ \\
\hline
\end{tabular}

Number Connection Test-B is positive in 60 patients in the study group only.

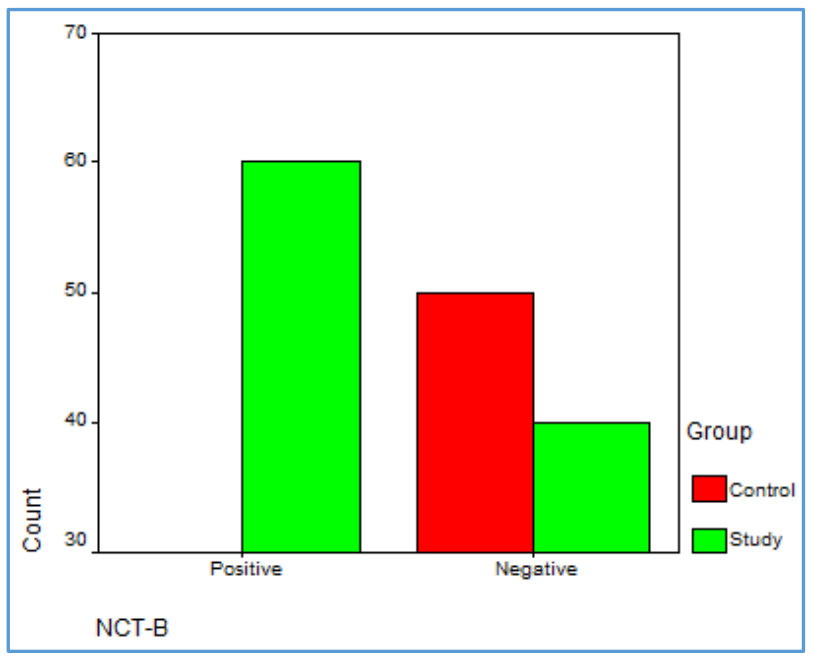

NCT -B was positivity in the study group only.

\section{DIGIT SYMBOL TEST}

\begin{tabular}{|c|c|c|c|c|c|}
\hline & & \multicolumn{2}{|c|}{ Group } & \multirow{2}{*}{ Total } \\
\hline & & & Control & Study & \\
\hline \multirow{6}{*}{ DST } & \multirow{3}{*}{$+\mathrm{Ve}$} & Count & 3 & 67 & 70 \\
\hline & & $\begin{array}{c}\text { \% within } \\
\text { DST }\end{array}$ & $4.3 \%$ & $95.7 \%$ & $100.0 \%$ \\
\hline & & $\begin{array}{c}\text { \% within } \\
\text { Group }\end{array}$ & $6.0 \%$ & $67.0 \%$ & $46.7 \%$ \\
\hline & \multirow{3}{*}{-Ve } & Count & 47 & 33 & 80 \\
\hline & & $\begin{array}{c}\text { \% within } \\
\text { DST }\end{array}$ & $58.8 \%$ & $41.3 \%$ & $100.0 \%$ \\
\hline & & $\begin{array}{c}\text { \% within } \\
\text { Group }\end{array}$ & $94.0 \%$ & $33.0 \%$ & $53.3 \%$ \\
\hline \multirow{3}{*}{\multicolumn{2}{|c|}{ Total }} & Count & 50 & 100 & 150 \\
\hline & & $\begin{array}{c}\text { \% within } \\
\text { DST }\end{array}$ & $33.3 \%$ & $66.7 \%$ & $100.0 \%$ \\
\hline & & $\begin{array}{c}\text { \% within } \\
\text { Group }\end{array}$ & $100.0 \%$ & $100.0 \%$ & $100.0 \%$ \\
\hline
\end{tabular}

There were totally 70 patients who showed positivity for Digit Symbol Test among which 67 people (95.7\%) were from the study group with the remaining 3 people $(4.3 \%)$ from the control group.

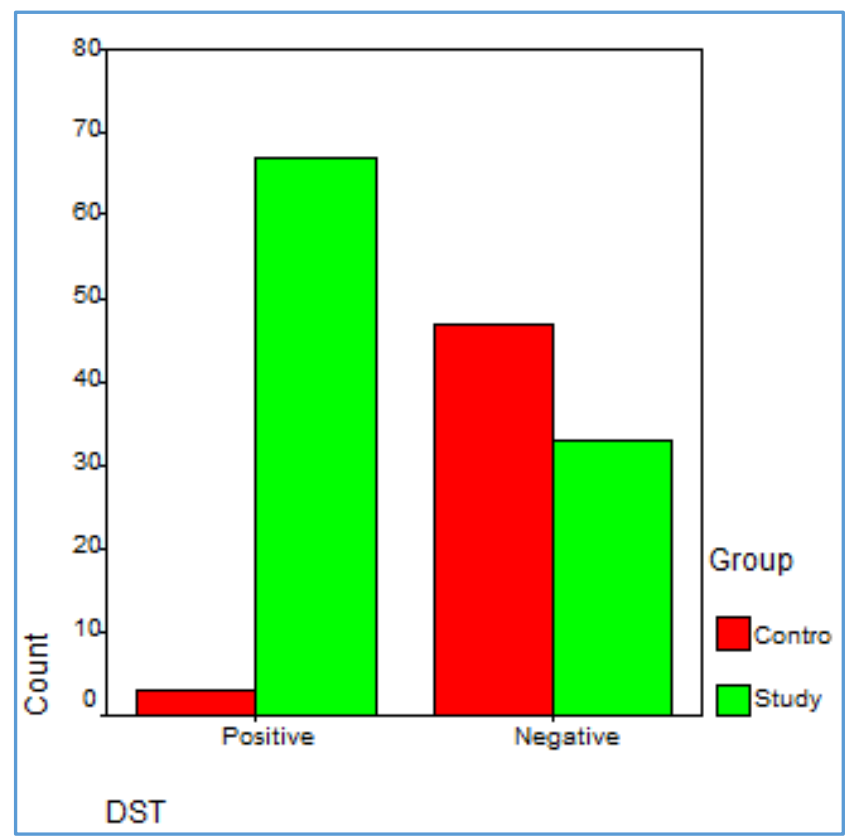


Predominantly, there were more positive people from the study group.

\section{LINE TRACING TEST (LTT)}

\begin{tabular}{|c|c|c|c|c|c|}
\hline & & \multicolumn{2}{|c|}{ Group } & \multirow{2}{*}{ Total } \\
\hline & & & Control & Study & \\
\hline \multirow{6}{*}{ LTT } & \multirow{3}{*}{$+\mathrm{Ve}$} & Count & 1 & 74 & 75 \\
\hline & & $\begin{array}{c}\text { \% within } \\
\text { LTT }\end{array}$ & $1.3 \%$ & $98.7 \%$ & $100.0 \%$ \\
\hline & & $\begin{array}{c}\text { \% within } \\
\text { Group }\end{array}$ & $2.0 \%$ & $74.0 \%$ & $50.0 \%$ \\
\hline & \multirow{3}{*}{$-\mathrm{Ve}$} & Count & 49 & 26 & 75 \\
\hline & & $\begin{array}{c}\text { \% within } \\
\text { LTT }\end{array}$ & $65.3 \%$ & $34.7 \%$ & $100.0 \%$ \\
\hline & & $\begin{array}{c}\text { \% within } \\
\text { Group }\end{array}$ & $98.0 \%$ & $26.0 \%$ & $50.0 \%$ \\
\hline \multirow{3}{*}{\multicolumn{2}{|c|}{ Total }} & Count & 50 & 100 & 150 \\
\hline & & $\begin{array}{c}\text { \% within } \\
\text { LTT }\end{array}$ & $33.3 \%$ & $66.7 \%$ & $100.0 \%$ \\
\hline & & $\begin{array}{l}\text { \% within } \\
\text { Group }\end{array}$ & $100.0 \%$ & $100.0 \%$ & $100.0 \%$ \\
\hline
\end{tabular}

Totally, 75 patients were positive for LTT out of which 74 $(98.7 \%)$ people were from the study group.

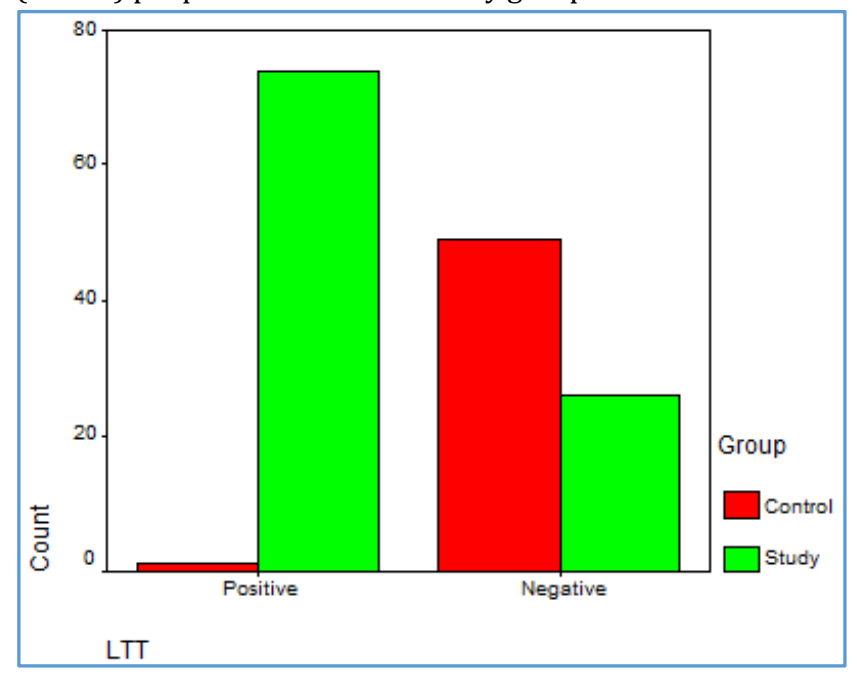

Almost, Line tracing test was positive in the study group leaving a fraction of positivity to the control group.

\section{SERIAL DOTTING TEST (SDT)}

\begin{tabular}{|c|c|c|c|c|c|}
\hline & & \multicolumn{2}{|c|}{ Group } & \multirow{2}{*}{ Total } \\
\hline & & & Control & Study & \\
\hline \multirow{6}{*}{ SDT } & \multirow{3}{*}{$+\mathrm{Ve}$} & Count & 3 & 70 & 73 \\
\hline & & $\begin{array}{l}\text { \% within } \\
\text { LTT }\end{array}$ & $4.1 \%$ & $95.9 \%$ & $100.0 \%$ \\
\hline & & $\begin{array}{l}\% \text { within } \\
\text { Group }\end{array}$ & $6.0 \%$ & $64.0 \%$ & $48.7 \%$ \\
\hline & \multirow{3}{*}{$-V e$} & Count & 47 & 30 & 77 \\
\hline & & $\begin{array}{c}\text { \% within } \\
\text { LTT }\end{array}$ & $61.1 \%$ & $38.9 \%$ & $100.0 \%$ \\
\hline & & $\begin{array}{l}\text { \% within } \\
\text { Group }\end{array}$ & $94.0 \%$ & $30 \%$ & $51.3 \%$ \\
\hline \multirow{3}{*}{\multicolumn{2}{|c|}{ Total }} & Count & 50 & 100 & 150 \\
\hline & & $\begin{array}{c}\text { \% within } \\
\text { LTT }\end{array}$ & $33.3 \%$ & $66.7 \%$ & $100.0 \%$ \\
\hline & & $\begin{array}{l}\% \text { within } \\
\text { Group }\end{array}$ & $100.0 \%$ & $100.0 \%$ & $100.0 \%$ \\
\hline
\end{tabular}

There were totally 73 people who showed positivity for Serial Dotting Test out of which 70 people (95.9\%) were from the study group while the remaining 3 people $(4.1 \%)$ were from the control group.

\section{CRITICAL FLICKER FREQUENCY (CFF)}

\begin{tabular}{|c|c|c|c|c|c|}
\hline & & \multicolumn{2}{|c|}{ Group } & \multirow{2}{*}{ Total } \\
\hline & & & Control & Study & \\
\hline \multirow{6}{*}{$\begin{array}{c}\text { CFF } \\
(\mathrm{Hz})\end{array}$} & \multirow{3}{*}{$\begin{array}{c}\text { Positive } \\
(<39 \\
\mathrm{Hz})\end{array}$} & Count & 4 & 73 & 77 \\
\hline & & $\begin{array}{c}\% \\
\text { within } \\
\text { CFF } \\
(\mathrm{Hz})\end{array}$ & $5.2 \%$ & $94.8 \%$ & $100.0 \%$ \\
\hline & & $\begin{array}{c}\% \\
\text { within } \\
\text { Group }\end{array}$ & $8.0 \%$ & $73.0 \%$ & $51.3 \%$ \\
\hline & \multirow{3}{*}{$\begin{array}{c}\text { Negative } \\
(>39 \\
\mathrm{Hz})\end{array}$} & Count & 46 & 27 & 73 \\
\hline & & $\begin{array}{c}\% \\
\text { within } \\
\text { CFF } \\
(\mathrm{Hz})\end{array}$ & $63.0 \%$ & $37.0 \%$ & $100.0 \%$ \\
\hline & & $\begin{array}{c}\% \\
\text { within } \\
\text { Group }\end{array}$ & $92.0 \%$ & $27.0 \%$ & $48.7 \%$ \\
\hline \multirow{3}{*}{\multicolumn{2}{|c|}{ Total }} & Count & 50 & 100 & 150 \\
\hline & & $\begin{array}{c}\% \\
\text { within } \\
\text { CFF } \\
(\mathrm{Hz})\end{array}$ & $33.3 \%$ & $66.7 \%$ & $100.0 \%$ \\
\hline & & $\begin{array}{c}\% \\
\text { within } \\
\text { Group }\end{array}$ & $100.0 \%$ & $100.0 \%$ & $100.0 \%$ \\
\hline
\end{tabular}

There were 73 patients $(94.8 \%)$ who turned out to be positive among the study group, and 4 patients (5.2\%) from the control group were positive in the study.

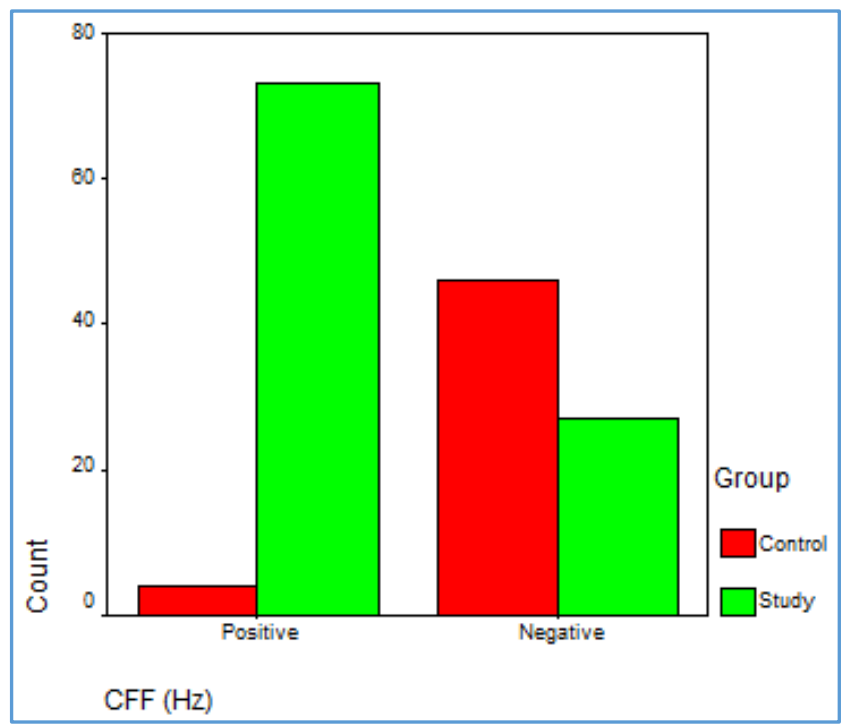

Flicker Frequency Test ( $\mathrm{p}$ value $=0$ ).

Critical Flicker Frequency Test was more positive in the study group than the control group. Only a few positives were noted among the control group.

\section{SUMMARY}

In our study, 100 patients who have been diagnosed and proven as a case of cirrhosis were included under the study 
group and 50 other people were included as control group without any evidence of liver disease. Before the study was commenced, all the people in both groups were clinically examined and were ruled out of any neuropsychological abnormalities. We utilised the psychometric tests in the study group and compared with the age, sex and education wise matched. In addition, critical flicker frequency test was carried out in both the study groups and the results were compared for further analysis. ${ }^{2}$

In our study, there was a preponderance of males in both the study groups with 76 males in the study group comprising $76 \%$ and 32 males in the control group as $64 \%$ of the members in their groups.

Mean age of presentation is 40 years with the youngest being 19 years and oldest as 69 years. The mean age of the study group is 41 years while that of the controls is 40 years.

Performances of the psychometric tests among the study group and the control group yielded significant results among the study group $(\mathrm{p}=0.000)$.

Critical Flicker Frequency Test was more positive in the study group than the control group and was found to be statistically significant values obtained as 0.000 indicating the higher significance when compared with the controls. Both the psychometric and critical flicker frequency tests were useful in detecting cases of minimal hepatic encephalopathy. Critical flicker frequency test was found to be more positive among the study group with $73 \%$ than the control group and hence the ability to detect the cases of minimal hepatic encephalopathy than the psychometric test. ${ }^{3}$

\section{CONCLUSION}

Our study demonstrated the occurrence of Minimal Hepatic Encephalopathy (MHE) in patients with Cirrhosis irrespective of the aetiology even in the presence of stable clinical condition. Both Critical Flicker Frequency (CFF) and
Psychometric tests have been found out to be effective in detecting MHE. Psychometric tests have subjective variations due to their age factor, differences in education while CFF Test has no such limitations and more of objective in nature not requiring any educational qualification for undergoing and interpretation of the light stimulus and is reproducible. The detection of MHE in more numbers in our study may be due to higher number of patients with higher classes of Child-Pugh classification. The presence of majority of the patients with Hepatitis B infection is due to our place of study being a tertiary care and a prestigious institute of Gastroenterology. ${ }^{4}$

Hence, we would like to recommend the utilisation of Critical Flicker Frequency (CFF) Test as an Outpatient Department based screening procedure and also for the monitoring of patients with cirrhosis yet with a stable clinical condition so as to detect MHE earlier and promptly institute the therapy to avoid the complications. ${ }^{5}$

\section{REFERENCES}

1. Weissenborn K. Diagnosis of encephalopathy. Digestion 1998;59 (Suppl 2):22-4.

2. Montagnese S, Middleton B, Skene DJ, et al. Night-time sleep disturbance does not correlate with neuropsychiatric impairment in patients with cirrhosis. Liver Int 2009;29(9):1372-82.

3. Challenger F, Walshe JM. Methyl mercaptan in relation to foetor hepaticus. Biochem J 1955;59(3):372-5.

4. Victor M, Adams RD, Cole M. The acquired (non-Wilsonian) type of chronic hepatocerebral degeneration. Medicine (Baltimore) 1965;44(5):345-96.

5. Krieger S, Jauss M, Jansen 0 , et al. Neuropsychiatric profile and hyperintense globus pallidus on T1-weighted magnetic resonance images in liver cirrhosis. Gastroenterology 1996;111(1):147-55. 